\title{
Upregulation of long noncoding RNA AP003419.16 predicts high risk of aging-associated idiopathic pulmonary fibrosis
}

\author{
XIAOYAN HAO, YUFENG DU, LI QIAN, DAN LI and XUEJUN LIU \\ Department of Geriatrics, The First Affiliated Hospital of Shanxi Medical University, Taiyuan, Shanxi 030001, P.R. China
}

Received November 29, 2016; Accepted July 3, 2017

DOI: $10.3892 / \mathrm{mmr} .2017 .7607$

\begin{abstract}
Long noncoding RNAs (lncRNAs) are able to regulate adjacent genes and thus participate in the incidence in the present study has identified lncRNA AP003419.16, adjacent to the protein-coding gene ribosomal protein S6 kinase B-2 (RPS6KB2). RPS6KB2 is believed to be involved in the process of aging and idiopathic pulmonary fibrosis (IPF), due to its activation by growth factors and regulation by the protein kinase mTOR signaling pathway. The results of the present study indicated that the expression of AP003419.16 increased significantly in patients with IPF, whereas its adjacent gene ribosomal protein S6 kinase B-2 increased simultaneously. AP003419.16 expression may be used to predict an increased risk of aging-associated IPF. The present study provided a molecular hypothesis of IPF occurrence in the aging process, in addition to novel molecular targets for the clinical treatment of IPF.
\end{abstract}

\section{Introduction}

The occurrence of tissue and organ fibrosis is a hallmark of the aging process, and pulmonary fibrosis is no exception. The replicative senescence of alveolar epithelial cells is a prominent pathological finding in idiopathic pulmonary fibrosis (IPF) $(1,2)$. IPF occurs primarily in the elderly, and the incidence of IPF is low in younger people (3). A previous study demonstrated that the occurrence of IPF may be associated with the epigenetic deregulation mechanisms, which are associated with aging (4). It has been previously reported

Correspondence to: Dr Xuejun Liu, Department of Geriatrics, The First Affiliated Hospital of Shanxi Medical University, 85 Jiefang South Road, Taiyuan, Shanxi 030001, P.R. China

E-mail: sydyylnbk@163.com

Abbreviations: IPF, idiopathic pulmonary fibrosis; lncRNA, long noncoding RNA; RT-qPCR, reverse transcription-quantitative polymerase chain reaction; RPS6KB2, ribosomal protein S6 kinase B-2; S6K, S6 kinase; TGF- $\beta 1$, transforming growth factor- $\beta 1$

Key words: long non-coding RNA, idiopathic pulmonary fibrosis, aging, protein kinase mTOR signaling pathway, adjacent genes that long non-coding RNAs (lncRNAs) may be associated with the occurrence of pulmonary fibrosis. A previous study observed that lncRNAs may regulate epithelial-mesenchymal transition in a bleomycin-induced rat model (5). LncRNAs may be involved in aging (6) and the regulation of aging-associated diseases (7). It has been previously reported that the protein kinase mTOR (mTOR) signaling pathway may have an important role in the aging process $(8,9)$. A number of factors are closely associated with aging, including stress, growth factors, nutritional status and energy supply, which affect the mTOR signaling pathway. Therefore, the mTOR signaling pathway may respond to various stimuli and alterations in the body during the aging process (10). Studies have demonstrated that lncRNAs and the mTOR signaling pathway are involved in the process of aging and IPF; therefore, the present study hypothesized that if there were alterations in the IncRNAs associated with mTOR, this may provide further evidence of the association between IPF and aging.

Transforming growth factor- $\beta 1$ (TGF- $\beta 1$ ) has been demonstrated to have a multifunctional role in IPF. It has been previously reported that TGF- $\beta 1$ is able to induce rapid senescence in A549 cells without significantly inhibiting cell growth, and may further direct A549 cells to enter a replicative senescent state (11). TGF- $\beta 1$ has an important function in the pathogenesis of IPF (12). Pulmonary fibrosis has been observed to occur in the elderly in clinical setting; however, the underlying mechanism remains to be elucidated.

Therefore, the present study aimed to investigate the differential expression of lncRNAs using high-throughput sequencing and bioinformatics analysis.

\section{Materials and methods}

Study population. According to diagnostic criteria established by the American Thoracic Society (13), 24 patients with IPF were selected. Simultaneously, 24 healthy controls

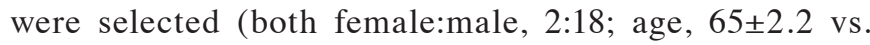
$65 \pm 3.8$ years). A total of 4 patients with IPF and 4 healthy controls (all males; age, $67 \pm 3.2$ vs. $64 \pm 2.8$ years; $\mathrm{P}>0.05$ ) were selected at random and $3 \mathrm{ml}$ venous blood was extracted for transcriptome sequencing and bioinformatics analysis. All the peripheral blood was snap-frozen in liquid nitrogen immediately following collection and stored at $-80^{\circ} \mathrm{C}$ prior to 
RNA extraction. Blood samples were obtained from patients and health controls at The First Affiliated Hospital of Shanxi Medical University from January 2016 to July 2016 (Taiyuan, China). All the methods were performed in accordance with the approved guidelines. The present study was approved by the Shanxi Medical University Ethics Committee. Written informed consent was obtained from patients and healthy individuals.

RNA extraction and sequencing. Total RNA was extracted from blood samples using TRIzol reagent (Invitrogen; Thermo Fisher Scientific, Inc., Waltham, MA, USA), according to the manufacturer's protocol. The integrity of the RNA was evaluated using a NanoDrop ND-1000 spectrophotometer (NanoDrop Technologies; Thermo Fisher Scientific, Inc., Wilmington, DE, USA) and standard denaturing $1 \%$ agarose gel electrophoresis. RNA libraries were constructed using rRNA-depleted RNAs with the TruSeq Stranded Total RNA Library Prep kit (Illumina, Inc., San Diego, CA, USA), according to the manufacturer's protocol.

Total RNA $(1 \mu \mathrm{g})$ was used to remove the rRNAs using the Ribo-Zero Gold kit (Illumina, Inc.). Libraries of $10 \mathrm{pM}$ were denatured as single-stranded DNA molecules, captured on Illumina flow cells, amplified in situ as clusters and finally sequenced for 150 cycles on an Illumina HiSeq Sequencer (Illumina, Inc.) according to the manufacturer's protocol. Cutadapt version 1.9 (14) and TopHat software (version 2.0.13) (15) were used to further analyze the results. Subsequently, cuffdiff (version 2.2.1) (cole-trapnell-lab.github .io/cufflinks/cuffdiff) was used to obtain the gene level in fragments per kilobase of transcript per million mapped reads (FPKM), as the expression profiles of IncRNAs and mRNAs, and fold-changes and q-values were calculated based on the FPKM. Differentially-expressed lncRNAs and mRNAs were identified.

Gene ontology (GO) analysis and pathway analysis. GO and Kyoto Encyclopedia of Genes and Genomes (KEGG) pathway analyses were performed to facilitate the elucidation of the biological implications of unique genes, and to identify significant pathways in the present study (16). In order to elucidate the potential roles of differentially-expressed lncRNAs, the KEGG database (www.genome.jp/kegg) was used to identify significant pathways for predicted target genes. GO term enrichment and the biological pathways used significant $\mathrm{P}$-values $(\mathrm{P}<0.05)$ associated with the target genes of differentially-expressed lncRNAs. Pathway analysis is a functional analysis which facilitates the mapping of genes to KEGG pathways. The NCBI database (www.ncbi .nlm.nih.gov/) records gene-specific information, including gene naming, map location, gene product and its properties, markers, phenotype and sequences, and this information was available to the present study. Ensembl database (www .ensembl.org/index.html) has been used for the annotation, analysis and display of vertebrate genomes in the present study. Differentially-expressed mRNA pathway analysis may be used to infer their biological functions. The Fisher P-value denotes the significance of the correlation of the pathway to the condition. $\mathrm{P}<0.05$ was considered to be the threshold for significance.
A549 cells in culture and $\beta$-galactosidase activity. A549 (American Type Culture Collection, Manassas, VA, USA) cells are adenocarcinomic human alveolar basal epithelial cells. The A549 cells used in the present study were cultured in RPMI 1640 (Gibco; Thermo Fisher Scientific, Inc.) medium. All medium was supplemented with $10 \%$ fetal bovine serum (Gibco; Thermo Fisher Scientific, Inc., Waltham, MA, USA), in a humidified air atmosphere of $5 \% \mathrm{CO}_{2}$ at $37^{\circ} \mathrm{C}$. Trypsin $(0.25 \%$ with $1 \mathrm{mM}$ EDTA; Invitrogen; Thermo Fisher Scientific, Inc.) was used to harvest the cells for further experiments.

A549 cells were seeded in 6-well plates, incubated for 7 day at $37^{\circ} \mathrm{C}$ and the cell culture medium was replaced every other day. TGF- $\beta 1$ (Austral Biologicals, San Ramon, CA, USA) was added every other day to the culture at a final concentration of $10 \mathrm{ng} / \mathrm{ml}$ (11). There were two groups in the present study: A549 cells and A549 cells treated with TGF- $\beta 1$ for 7 days.

X-gal (Wuhan Boster Biological Technology, Ltd., Wuhan, China) is a chromogenic substrate of $\beta$-galactosidase, which produces a blue product under the catalysis by $\beta$-galactosidase. Cells at a density of $1 \times 10^{6}$ cells per well in 6 -well plates were fixed in $3 \%$ formaldehyde at $4^{\circ} \mathrm{C}$ for $15 \mathrm{~min}$. Subsequently, the cells were then incubated with staining solution (composed of $40 \mathrm{mM}$ citric acid sodium phosphate, $1 \mathrm{mg} / \mathrm{ml} \mathrm{X-gal,} 5 \mathrm{mM}$ potassium ferricyanide, $150 \mathrm{mM} \mathrm{NaCl}$ and $2 \mathrm{mM} \mathrm{MgCl}_{2}$ ) at $37^{\circ} \mathrm{C}$ for $12 \mathrm{~h}$. $\beta$-galactosidase positive cells were enumerated by counting over 400 cells in three in dependent fields.

Validation of differential expression of IncRNA and mRNA with reverse transcription-quantitative polymerase chain reaction (RT-qPCR) analysis. In order to validate the sequencing results, the remaining twenty samples were analyzed to exclude the individual differences. A549 cells were used to validate the hypothesis that AP003419.16 and gene ribosomal protein S6 kinase B-2 (RPS6KB2) may be associated with aging and IPF.

Total RNA was prepared using TRIzol (Invitrogen; Thermo Fisher Scientific, Inc.) and reverse-transcribed using an RNA-to-cDNA kit (Takara Biotechnology Co., Ltd., Dalian, China). Reverse transcription was performed to convert the extracted RNA into cDNA with an oligo (dT) primer (Takara Biotechnology Co., Ltd.) and reverse transcriptase Master mix (Takara Biotechnology Co., Ltd.) and incubated at $37^{\circ} \mathrm{C}$ for $15 \mathrm{~min}$ and $85^{\circ} \mathrm{C}$ for $5 \mathrm{sec}$. RT-qPCR analysis is the gold standard for data verification. The expression levels of lncRNAs and mRNAs were determined using SYBR Green I-based qPCR (Takara Biotechnology Co., Ltd.). The reaction conditions were $95^{\circ} \mathrm{C}$ for $10 \mathrm{~min}$, followed by 40 cycles of $95^{\circ} \mathrm{C}$ for $10 \mathrm{sec}$ and $60^{\circ} \mathrm{C}$ for $60 \mathrm{sec} . \beta$-actin was used as an endogenous control. Primer Premier version 5.0 (Primer Biosoft International, Palo Alto, CA, USA) was used to design the primers. The primers were as follows: AP003419.16 forward, TTAATCTTCCAC GGGAGCAG and reverse, GCTGTGAGAGCAGCAGGAC; RPS6KB2 forward, TCCACTCCTGCCACCGC and reverse, TCGCCACCTGCCTCACA; and $\beta$-actin forward, GTGGCC GAGGACTTTGATTG and reverse, CCTGTAACAACGCAT CTCATATT. The relative expression levels of AP003419.16 and RPS6KB2 were calculated using the comparative $2^{-\Delta \Delta C q}$ method (17).

Statistical analysis. All statistical data were analyzed using SPSS 17.0 software (SPSS, Inc., Chicago, IL, USA). Results 


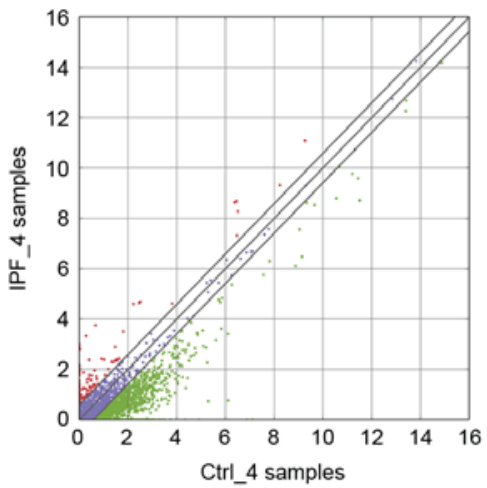

$\mathrm{D}$

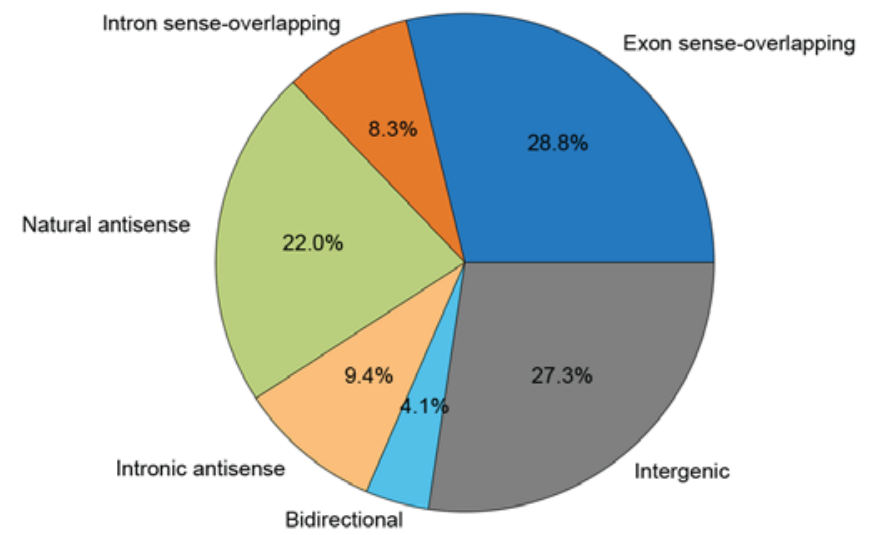

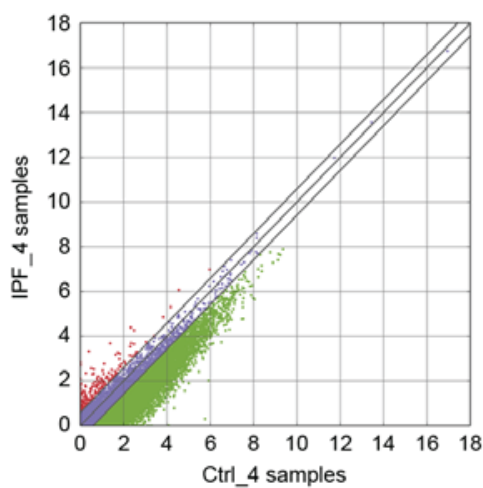

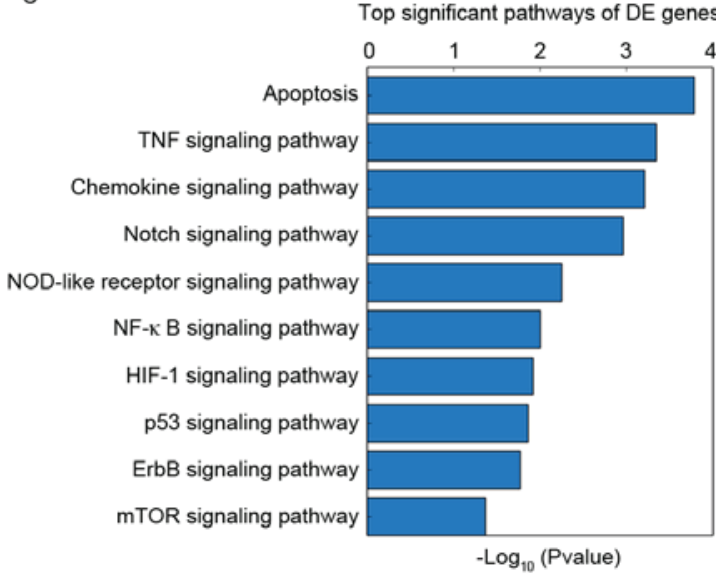

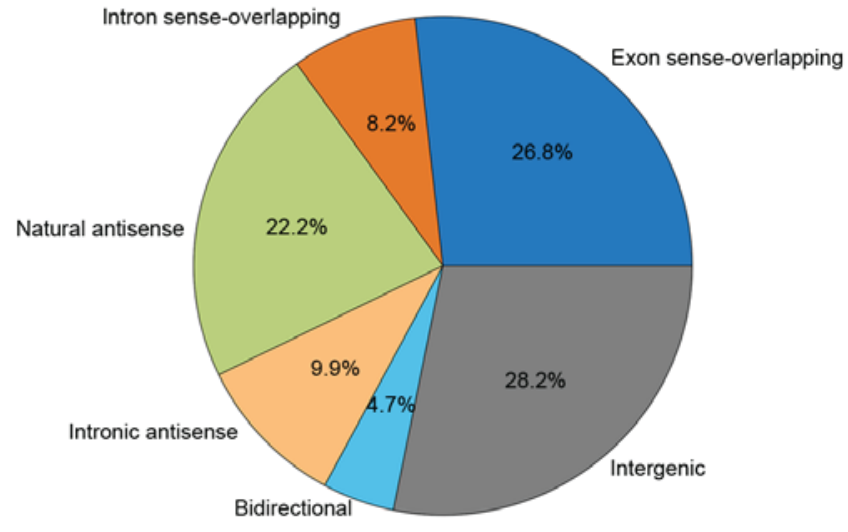

Figure 1. Bioinformatics analysis. (A) Differentially-expressed lncRNAs. A total of 440 lncRNAs that were upregulated and 1,376 lncRNAs that were downregulated in the IPF group. Red indicates high relative expression and green indicates low relative expression. Purple indicates no significant change. (B) Differentially-expressed mRNAs. There were 361 mRNAs that were upregulated and 1,124 mRNAs that were downregulated in the IPF group. Red indicates high relative expression and green indicates low relative expression. (C) Target enriched pathways. The abscissa represents the enrichment score. The mTOR signaling pathway was one of the significant pathways, according to the pathway analysis. (D) According to their position in the genome, which is associated with protein-coding genes, lncRNAs may be divided into six types: Exon sense-overlapping; intronic antisense; natural antisense; intergenic; bidirectional; and intron sense-overlapping. Natural antisense represented $22 \%$ of the total in the IPF group. (E) Natural antisense accounted for $22.2 \%$ in the control group. IncRNA, long noncoding RNA; IPF, idiopathic pulmonary fibrosis; mTOR, protein kinase mTOR; Ctrl, control.

are expressed as mean \pm standard deviation. Student's t-test were used for inter-group comparisons. $\mathrm{P}<0.05$ was considered to indicate a statistically significant difference.

\section{Results}

IncRNA and mRNA expression. Compared with the control group, it was observed that there were 440 lncRNAs that were upregulated and there were 1,376 lncRNAs that were downregulated in the IPF group. There were 1,816 differentially-expressed lncRNAs identified by this screening, as presented in Fig. 1A. A total of 12 differentially expressed lncRNAs were randomly selected (upregulated lncRNAs: AP003419.16, AB586698, ADSS, AF080092, AF520792, AK126278; downregulated 1ncRNAs: AB062083, ADAMTSL4-AS1, ADRM1, ADSL, AF063596, AJ276246) from the aberrantly-expressed lncRNAs for further analysis. The present study examined AP003419.16, which was upregulated in the transcriptome sequencing results. Compared with the control group, it was observed that there were 361 mRNAs that were upregulated and there were 1,124 mRNAs that were downregulated in the IPF group. There were 1,485 differentially-expressed mRNAs identified by this screening in Fig. 1B.

Pathway analysis. GO and KEGG pathway analysis of differentially-expressed mRNAs provided a measure of the critical function. The most enriched GO term was associated with regulation of chromosome segregation in the $\mathrm{GO}$ biological process analysis (Table I). Significant pathways (Table II; Fig. 1C) were identified for predicting the target lncRNA genes according to the KEGG database. The mTOR signaling pathway was observed to be associated with aging, in addition to with the IPF. According to the KEGG database, the Fisher P-value was $0.04(\mathrm{P}<0.05)$ and the enrichment score was 1.37. According to their position in the genome, which is associated with protein-coding genes, IncRNAs may be divided into six types: Exon sense-overlapping; intronic antisense; natural antisense; intergenic; bidirectional; and intron sense-overlapping $(18,19)$. According to the result of transcriptome sequencing and bioinformatics analysis in the the IPF group and the control group, it was found that natural antisense represented $22.0 \%$ of the total lncRNAs in the IPF group (Fig. 1D). Natural antisense accounted for $22.2 \%$ in the control group (Fig. 1E). 
Table I. Target gene-associated GO analysis.

A, Biological processes

\begin{tabular}{|c|c|c|c|c|c|}
\hline GO ID & Term & P-value & $\begin{array}{l}\text { Enrichment } \\
\text { score }\end{array}$ & List total & Genes \\
\hline GO:0000086 & $\begin{array}{l}\mathrm{G} 2 / \mathrm{M} \text { transition of } \\
\text { mitotic cell cycle }\end{array}$ & 0.000579 & 3.23 & 317 & $\begin{array}{l}\text { RAD51B, CCND1, AURKB, } \\
\text { PLK4, CIT, NEDD1, PLK1, } \\
\text { HAUS2, CCNB2, LIN52, } \\
\text { MELK }\end{array}$ \\
\hline GO:0051983 & $\begin{array}{l}\text { Regulation of } \\
\text { chromosome } \\
\text { segregation }\end{array}$ & 0.00027 & 3.566 & 317 & $\begin{array}{l}\text { BUB1, ESPL1, KNSTRN, } \\
\text { CDCA5, AURKB }\end{array}$ \\
\hline GO:0007063 & $\begin{array}{l}\text { Regulation of sister } \\
\text { chromatid cohesion }\end{array}$ & 0.001 & 2.95 & 317 & ESPL1, CDCA5, BUB1 \\
\hline
\end{tabular}

B, Cellular components

\begin{tabular}{lllclc}
\hline GO ID & \multicolumn{1}{c}{ Term } & P-value & $\begin{array}{c}\text { Enrichment } \\
\text { score }\end{array}$ & List total & Genes \\
\hline GO:0051233 & Spindle midzone & 0.0092 & 2.034 & 346 & CENPE, PLK1, BUB1B \\
GO:0005763 & $\begin{array}{l}\text { Mitochondrial small } \\
\text { ribosomal subunit }\end{array}$ & 0.005 & 2.284 & 346 & MRPS31, MRPS18C, \\
GO:0005758 & $\begin{array}{l}\text { Mitochondrial } \\
\text { intermembrane space }\end{array}$ & 0.009 & 2.01 & 346 & MRPS3 \\
& & & & TIMM10, TIMM8B, SLMO2, \\
\end{tabular}

GO, gene ontology.

Target lncRNA. RPS6KB2 is involved in the process of aging and pulmonary fibrosis, given its activation by growth factors and its regulation by the mTOR signaling pathway. RPS6KB2 is an important molecule in the mTOR signaling pathway (Table II). It was demonstrated that the adjacent gene mRNA to RPS6KB2 was AP003419.16, using bioinformatics analysis. AP003419.16 is located on chromosome 11 at approximate locations (chr11: 67195930-67202872), and the adjacent gene is RPS6KB2. According to the result of our transcriptome sequencing and bioinformatics analysis in the the IPF group and the control group, it was found that the lncRNA AP003419.16 is one of the differentially expressed lncRNAs, and the fold change between two groups was 1.92. According to the Ensembl database, the gene ID of AP003419.16 is ENSG00000255949, which is 470 bp in length and the biotype is antisense.

A549 cells. A549 cells were polygonal in the normal state (Fig. 2A). When cultured in the presence of $10 \mathrm{ng} / \mathrm{ml}$ TGF- $\beta 1$ for 7 days, A549 cells exhibited rapid morphological change (Fig. 2B). A marked increase in the X-gal positive A549 cells was observed following the addition of TGF- $\beta 1$ for 7 days. TGF- $\beta 1$ was able to direct A549 cells to a replicative senescent state (Fig. 3).

$R T$ - $P$ PCR validation. In order to validate the results independently and to determine the role of lncRNAs in patients with
IPF, RT-qPCR analysis was used. AP003419.16 and RPS6KB2 were highly expressed in the 20 patients with IPF and exhibited reduced expression in the control group, according to the results of the RT-qPCR (Fig. 4; P<0.05). Similarly, AP003419.16 and RPS6KB2 were recorded at higher expression levels in TGF- $\beta 1$-treated A549 cells compared with the control group (Fig. 5; $\mathrm{P}<0.05$ ).

\section{Discussion}

The clinical treatment for IPF predominantly relies on ventilator maintenance, although outcomes are poor. According to the American Thoracic Society treatment principles, the treatment of choice for IPF is lung transplantation (20). However, due to high cost of treatment and short survival time, lung transplantation represents a psychological and economic burden on patients with IPF and their families. Understanding the regulatory functions of lncRNAs in lung fibroblasts may provide novel insights for IPF therapy.

LncRNAs are transcribed RNAs that are $>200$ nucleotides long. Previous studies have suggested that lncRNAs may act as competitive endogenous RNAs and are involved in physiological and pathological processes (21-23) According to their position in the genome, which is associated with protein-coding genes, lncRNAs may be divided into six types $(18,19)$ : Exon sense-overlapping; intronic antisense; natural antisense; intergenic; bidirectional; and intron 
Table II. Target gene-associated pathways.

\begin{tabular}{|c|c|c|c|c|c|c|}
\hline $\begin{array}{l}\text { Pathway } \\
\text { ID }\end{array}$ & Definition & P-value & $\begin{array}{l}\text { Selection } \\
\text { counts }\end{array}$ & Size & $\begin{array}{l}\text { Enrichment } \\
\text { score }\end{array}$ & Genes \\
\hline hsa04150 & $\begin{array}{l}\text { mTOR signaling } \\
\text { pathway }\end{array}$ & 0.04 & 20 & 6,890 & 1.37 & $\begin{array}{l}\text { AKT1, AKT2, EIF4E2, IKBKB, IRS1, } \\
\text { MAPK3, PDPK1, PIK3CD, PIK3R5, } \\
\text { PRKCA, PRKCB, RPS6KA2, RPS6KB2, } \\
\text { RRAGA, STK11, STRADA, TNF, TSC2, } \\
\text { ULK1, ULK3 }\end{array}$ \\
\hline hsa04923 & $\begin{array}{l}\text { Regulation of lipolysis } \\
\text { in adipocytes }\end{array}$ & 0.033 & 4 & 6,890 & 1.474 & PIK3R3, PLA2G16, PRKG1, TSHR \\
\hline hsa04012 & $\begin{array}{l}\text { ErbB signaling } \\
\text { pathway }\end{array}$ & 0.02 & 29 & 6,890 & 1.77 & $\begin{array}{l}\text { AKT1, AKT2, ARAF, CAMK2G, } \\
\text { CDKN1A, CDKN1B, CRK, CRKL, } \\
\text { ELK1, GRB2, GSK3B, HRAS, MAP2K7, } \\
\text { MAPK3, MYC, NCK1, NCK2, PAK2, } \\
\text { PIK3CD, PIK3R5, PLCG1, PRKCA, } \\
\text { PRKCB, RPS6KB2, SHC1, SRC, STAT5A, } \\
\text { STAT5B, TGFA }\end{array}$ \\
\hline hsa04621 & $\begin{array}{l}\text { NOD-like receptor } \\
\text { signaling pathway }\end{array}$ & 0.005 & 22 & 6,890 & 2.252 & $\begin{array}{l}\text { CARD6, CARD8, CARD9, CASP5, } \\
\text { CASP8, CHUK, CXCL1, IKBKB, } \\
\text { MAPK13, MAPK14, MAPK3, MEFV, } \\
\text { NFKB1, NLRP1, NLRP3, NOD1, NOD2, } \\
\text { PSTPIP1, PYCARD, RELA, SUGT1, TNF }\end{array}$ \\
\hline hsa05133 & Pertussis & 0.02 & 5 & 6,890 & 1.65 & C4BPA, C5, CASP7, IL10, IL12A \\
\hline hsa04330 & $\begin{array}{l}\text { Notch signaling } \\
\text { pathway }\end{array}$ & 0.001 & 21 & 6,890 & 2.96 & $\begin{array}{l}\text { APH1A, CREBBP, CTBP2, DTX1, } \\
\text { DTX3, DVL1, DVL2, DVL3, HDAC1, } \\
\text { HDAC2, JAG2, KAT2A, LFNG, MFNG, } \\
\text { NCOR2, NCSTN, NOTCH1, NOTCH2, } \\
\text { NUMB, PSENEN, RFNG }\end{array}$ \\
\hline
\end{tabular}

A

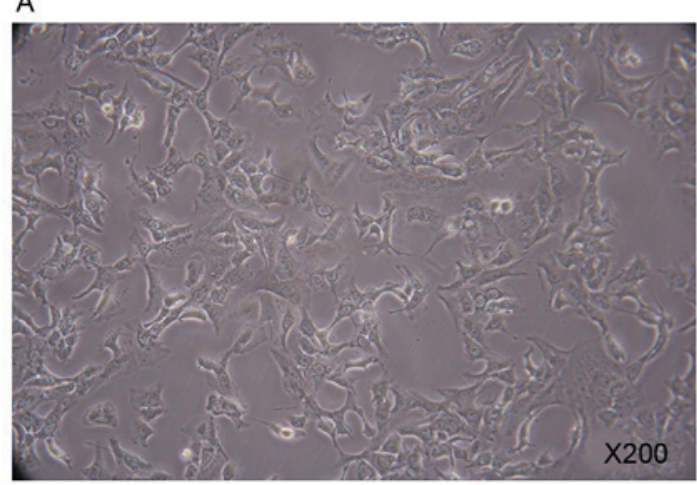

B

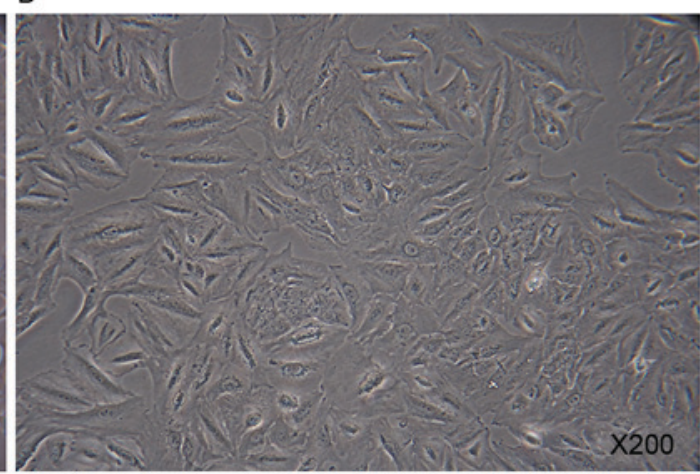

Figure 2. Observation of A549 cells. (A) A549 cells in the control group were polygonal. Magnification, x200. (B) A549 cells rapidly underwent a morphological change, following culturing in the presence of $10 \mathrm{ng} / \mathrm{ml}$ transforming growth factor- $\beta 1$ for 7 days. Magnification, $\mathrm{x} 200$.

sense-overlapping. LncRNAs are able to regulate gene expression through various mechanisms as follows (24): LncRNA transcription may interfere with the expression of adjacent genes; or, it may act via the transcription of protein-coding genes to form complementary double-stranded regulatory gene expression. The expression levels of specific lncRNAs may be altered during the progression of a disease; therefore, they may be used as a marker for its diagnosis. LncRNAs are able to regulate adjacent genes and thus contribute to the incidence of associated diseases (25). Antisense lncRNAs may form stable double-stranded structures with adjacent mRNAs and regulate their expression to facilitate the development of disease (26). Antisense lncRNAs are able to regulate the inhibitory effect of microRNAs on adjacent mRNAs in the development of disease (27). Antisense lncRNAs are involved in the regulation of aging-associated 
A

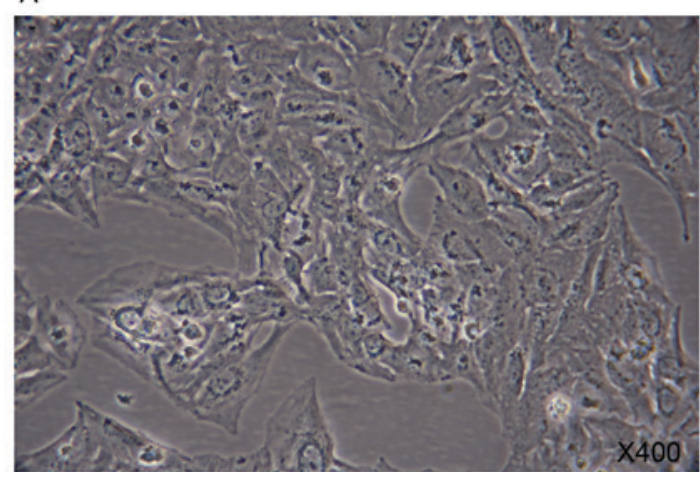

B

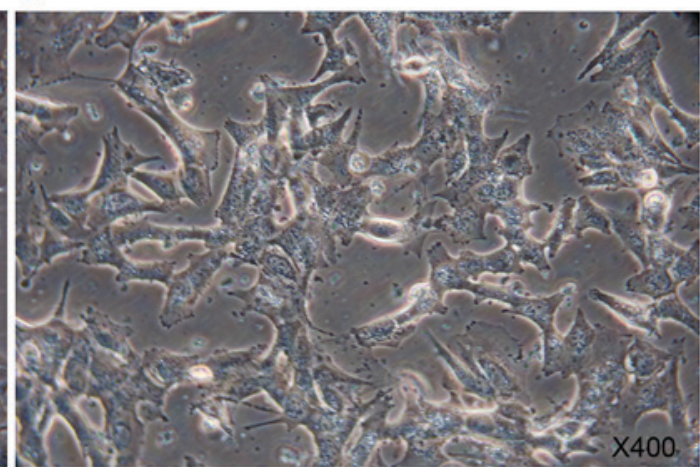

Figure 3. Analysis of $\beta$-galactosidase activity. (A) A549 cells in the control group Magnification, $x 400$. (B) $\beta$-galactosidase activity, a marked increase in the number of X-gal-positive A549 cells was observed following treatment with transforming growth factor- $\beta 1$ for 7 days. Magnification, $\mathrm{x} 400$.

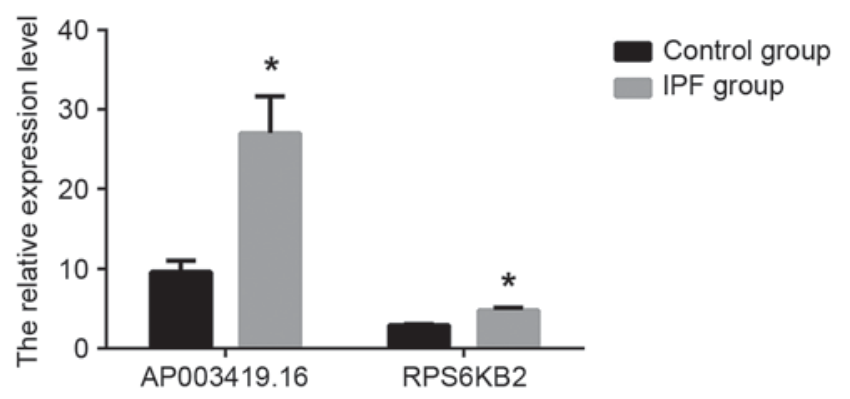

Figure 4. Validation of AP003419.16 and RPS6KB2 microarray data using reverse transcription-quantitative polymerase chain reaction analysis. The relative expression levels of AP003419.16 and RPS6KB2 were normalized. Data are expressed as the mean \pm standard deviation $(* \mathrm{P}<0.05$ vs. control). RPS6KB2, ribosomal protein S6 kinase B-2; IPF, idiopathic pulmonary fibrosis.

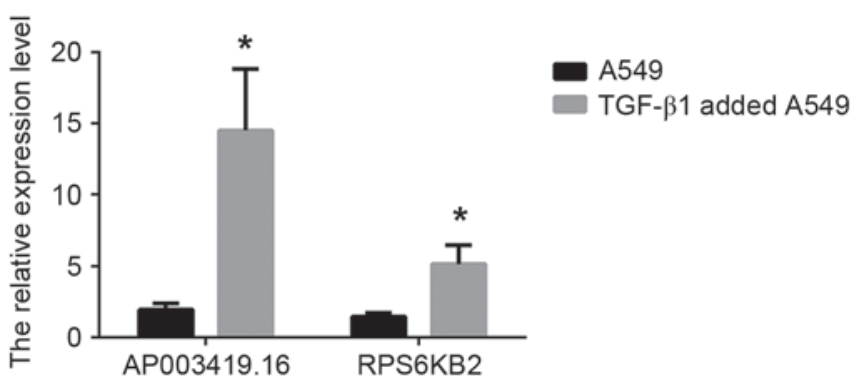

Figure 5. Validation of AP003419.16 and RPS6KB2 data by reverse transcription-quantitative polymerase chain reaction analysis at the cellular level. The relative expression levels of AP003419.16 and RPS6KB2 were normalized and the data displayed in the histograms are expressed as the mean \pm standard deviation ( $\mathrm{P}<0.05$ vs. control). RPS6KB2, ribosomal protein S6 kinase B-2; TGF- $\beta 1$, transforming growth factor- $\beta 1$.

diseases $(28,29)$ and aging-associated pathways $(30)$. A previous study observed that lncRNAs may regulate pulmonary fibrosis during pulmonary epithelial cell transformation in a pulmonary fibrosis animal model (5). It has additionally been reported that the silencing of IncRNAs may inhibit cell proliferation and $\alpha$-smooth muscle actin expression, whilst increasing collagen expression, in pulmonary fibroblasts (31). These previous findings suggested that lncRNAs may be involved in the occurrence of aging and IPF.
Rapamycin, an anti-aging drug, is effective in extending mammalian life and in the treatment of diseases, including premature aging (32). In a bleomycin-established IPF animal model, lung epithelial cells were protected by mTOR signaling pathway inhibitors, which may have therapeutic implications in pulmonary fibrosis $(33,34)$. mTOR has been previously reported to be associated with collagen production in IPF and promote the pathogenesis of IPF (35). mTOR expression has been observed to be associated with the degree of pulmonary fibrosis in IPF (36).

According to the KEGG pathway analysis performed by the present study, RPS6KB2 is an important gene in the mTOR signaling pathway. According to the NCBI database, the protein encoded by the mRNA is a ribosomal S6 kinase (S6K), which contains a kinase catalytic domain and may phosphorylate the $\mathrm{S} 6$ ribosomal protein. RPS6KB2 primarily regulates cell senescence and the cell cycle through phosphorylation of S6K. S6K is involved in regulating the physiological processes of DNA replication and translation. RPS6KB2 is associated with aging and pulmonary fibrosis. The S6K pathway is involved in the progression of pulmonary fibrosis (37).

High-throughput sequencing and bioinformatics analysis performed in the present study identified AP003419.16 to be adjacent to the protein-coding gene RPS6KB2. RPS6KB2 is believed to be involved in the process of aging and pulmonary fibrosis, due to its activation by growth factors and regulation by the mTOR signaling pathway. The expression levels of AP003419.16 and RPS6KB2 were higher in the 20 patients with IPF compared with the control group, as demonstrated by RT-qPCR analysis.

TGF- $\beta 1$ has an important role in the pathogenesis of IPF, and is considered to be an important profibrotic factor $(38,39)$. The results of the present study demonstrated a marked increase in the number of X-gal-positive A549 cells following treatment with TGF- $\beta 1$ for 7 days. TGF- $\beta 1$ was additionally demonstrated to direct A549 cells to a replicative senescent state. AP003419.16 and RPS6KB2 were highly expressed in TGF- $\beta 1$-treated A549 cells compared with the control group. Therefore, IPF may be associated with senescence at the cellular level.

The present study demonstrated that the expression of AP003419.16 increased significantly in patients with IPF, while its adjacent gene RPS6KB2 increased simultaneously. 
Analysis of the expression of AP003419.16 may predict an increased risk of aging-associated IPF. The findings of the present study elucidated a molecular hypothesis of IPF progression in the aging process and provided novel molecular targets for clinical treatment of IPF.

\section{References}

1. Cookson WO and Moffatt MF: Bedside to gene and back in idiopathic pulmonary fibrosis. N Engl J Med 368: 2228-2230, 2013.

2. Fernandez IE and Eickelberg O: New cellular and molecular mechanisms of lung injury and fibrosis in idiopathic pulmonary fibrosis. Lancet 380: 680-688, 2012

3. Puglisi S, Torrisi S, Giuliano R, Vindigni V and Vancheri C: What we know about the pathogenesis of idiopathic pulmonary fibrosis. Semin Respir Crit Care Med 37: 358-367, 2016.

4. King TE, Pardo A and Selman M: Idiopathic pulmonary fibrosis Lancet 378: 1949-1961, 2011.

5. Sun H, Chen J, Qian W, Kang J, Wang J, Jiang L, Qiao L, Chen W and Zhang J: Integrated long non-coding RNA analyses identify novel regulators of epithelial-mesenchymal transition in the mouse model of pulmonary fibrosis. J Cell Mol Med 20: 1234-1246, 2016.

6. Puvvula PK, Desetty RD, Pineau P, Marchio A, Moon A, Dejean $\mathrm{A}$ and Bischof $\mathrm{O}$ : Long noncoding RNA PANDA and scaffold-attachment-factor SAFA control senescence entry and exit. Nat Commun 5: 5323, 2014.

7. Szafranski K, Abraham KJ and Mekhail K: Non-coding RNA in neural function, disease and aging. Front Genet 6: 87, 2015.

8. Magnuson B, Ekim B and Fingar DC: Regulation and function of ribosomal protein $\mathrm{S} 6$ kinase (S6K) within mTOR signalling networks. Biochem J 441: 1-21, 2012.

9. Selman C, Tullet JM, Wieser D, Irvine E, Lingard SJ, Choudhury AI, Claret M, Al-Qassab H, Carmignac D, Ramadani F, et al: Ribosomal protein S6 kinase 1 signaling regulates mammalian life span. Science 326 : $140-144,2009$.

10. Sharp ZD: Aging and TOR: Interwoven in the fabric of life. Cell Mol Life Sci 68: 587-597, 2011.

11. Katakura Y, Nakata E, Miura T and Shirahata S: Transforming growth factor $\beta$ triggers two independent-senescence programs in cancer cells. Biochem Biophys Res Commun 255: 110-115, 1999.

12. Qu Y, Zhang L, Kang Z, Jiang W and Lv C: Ponatinib ameliorates pulmonary fibrosis by suppressing TGF- $\beta 1 / \mathrm{Smad} 3$ pathway. Pulm Pharmacol Ther 34: 1-7, 2015.

13. Raghu G, Rochwerg B, Zhang Y, Garcia CA, Azuma A, Behr J, Brozek JL, Collard HR, Cunningham W, Homma S, et al: An official ATS/ERS/JRS/ALAT clinical practice guideline: Treatment of idiopathic pulmonary fibrosis. Am J Respir Crit Care Med 192: e3-e19, 2015.

14. Martin M: Cutadapt removes adapter sequences from high-throughput sequencing reads. EMBnet J 17: 10-12, 2011

15. Kim D, Pertea G, Trapnell C, Pimentel H, Kelley R and Salzberg SL: TopHat2: Accurate alignment of transcriptomes in the presence of insertions, deletions and gene fusions. Genome Bio 14: R36, 2013.

16. Ashburner M, Ball CA, Blake JA, Botstein D, Butler $\mathrm{H}$, Cherry JM, Davis AP, Dolinski K, Dwight SS, Eppig JT, et al: Gene Ontology: Tool for the unification of biology. Nature genetics 25: 25-29, 2000 .

17. Livak KJ and Schmittgen TD: Analysis of relative gene expression data using real-time quantitative PCR and the 2(-Delta Delta C(T)) method. Methods 25: 402-408, 2001.

18. Mercer TR, Dinger ME and Mattick JS: Long non-coding RNAs: Insights into functions. Nat Rev Genet 10: 155-159, 2009.

19. Ponting CP, Oliver PL and Reik W: Evolution and functions of long noncoding RNAs. Cell 136: 629-641, 2009.

20. De Oliveira NC , JulliardW, Osaki S, Maloney JD, Cornwell RD, Sonetti DA and Meyer KC: Lung transplantation for high-risk patients with idiopathic pulmonary fibrosis. Sarcoidosis Vasc Diffuse Lung Dis 33: 235-241, 2016.
21. Cesana M, Cacchiarelli D, Legnini I, Santini T, Sthandier O, Chinappi M, Tramontano A and Bozzoni I: A long noncoding RNA controls muscle differentiation by functioning as a competing endogenous RNA. Cell 147: 358-369, 2011.

22. Cheng EC and Lin H: Repressing the repressor: A lincRNA as a MicroRNA sponge in embryonic stem cell self-renewal. Dey Cell 25: 1-2, 2013.

23. Song X, Cao G, Jing L, Lin S, Wang X, Zhang J, Wang M, Liu W and Lv C: Analysing the relationship between lncRNA and protein-coding gene and the role of IncRNA as ceRNA in pulmonary fibrosis. J Cell Mol Med 18: 991-1003, 2014.

24. Wilusz JE, Sunwoo H and Spector DL: Long noncoding RNAs: Functional surprises from the RNA world. Genes Dev 23: 1494-1504, 2009.

25. Lee DY, Moon J, Lee S-T, Jung KH, Park DK, Yoo JS, Sunwoo JS, Byun JI, Shin JW, Jeon D, et al: Distinct expression of long non-coding RNAs in an Alzheimer's disease model. J Alzheimers Dis 45: 837-849, 2015

26. Faghihi MA, Modarresi F, Khalil AM, Wood DE, Sahagan BG, Morgan TE, Finch CE, St Laurent G III, Kenny PJ and Wahlestedt C: Expression of a noncoding RNA is elevated in Alzheimer's disease and drives rapid feed-forward regulation of $\beta$-secretase. Nat Med 14: 723-730, 2008.

27. Faghihi MA, Zhang M, Huang J, Modarresi F, Van der Brug MP, Nalls MA, Cookson MR, St-Laurent G III and Wahlestedt C: Evidence for natural antisense transcript-mediated inhibition of microRNA function. Genome Biol 11: R56, 2010

28. Carrieri C, Cimatti L, Biagioli M, Beugnet A, Zucchelli S, Fedele S, Pesce E, Ferrer I, Collavin L, Santoro C, et al: Long non-coding antisense RNA controls Uchl1 translation through an embedded SINEB2 repeat. Nature 491: 454-457, 2012.

29. Li X, Wu Z, Fu X and Han W: lncRNAs: Insights into their function and mechanics in underlying disorders. Mutat Res Rev Mutat Res 762: 1-21, 2014

30. Yang D, Lian T, Tu J, Gaur U, Mao X, Fan X, Li D, Li Y and Yang M: LncRNA mediated regulation of aging pathways in Drosophila melanogaster during dietary restriction. Aging (Albany NY) 8: 2182-2203, 2016.

31. Huang C, Yang Y and Liu L: Interaction of long noncoding RNAs and microRNAs in the pathogenesis of idiopathic pulmonary fibrosis. Physiol Genomics 47: 463-469, 2015.

32. Mendelsohn AR and Larrick JW: Rapamycin as an antiaging therapeutic? Targeting mammalian target of rapamycin to treat Hutchinson-Gilford Progeria and neurodegenerative diseases. Rejuvenation Res 14: 437-441, 2011.

33. Yoshizaki A, Yanaba K, Yoshizaki A, Iwata Y, Komura K, Ogawa F, Takenaka M, Shimizu K, Asano Y, Hasegawa M, et al: Treatment with rapamycin prevents fibrosis in tight-skin and bleomycin-induced mouse models of systemic sclerosis. Arthritis Rheum 62: 2476-2487, 2010.

34. Chang W, Wei K, Ho L, Berry GJ, Jacobs SS, Chang CH and Rosen GD: A critical role for the mTORC2 pathway in lung fibrosis. PLoS One 9: e106155, 2014.

35. Nho RS and Hergert P: IPF fibroblasts are desensitized to type I collagen matrix-induced cell death by suppressing low autophagy via aberrant Akt/mTOR kinases. PLoS One 9: e94616, 2014

36. Park JS, Park HJ, Park YS, Lee SM, Yim JJ, Yoo CG, Han SK and Kim YW: Clinical significance of mTOR, ZEB1, ROCK1 expression in lung tissues of pulmonary fibrosis patients. BMC Pulm Med 14: 168, 2014.

37. Madala SK, Thomas G, Edukulla R, Davidson C, Schmidt S, Schehr A and Hardie WD: p70 ribosomal S6 kinase regulates subpleural fibrosis following transforming growth factor- $\alpha$ expression in the lung. Am J Physiol Lung Cell Mol Physiol 310: L175-L186, 2016.

38. Li FZ, Cai PC, Song LJ, Zhou LL, Zhang Q, Rao SS, Xia Y, Xiang F, Xin JB, Greer PA, et al: Crosstalk between calpain activation and TGF- $\beta 1$ augments collagen-I synthesis in pulmonary fibrosis. Biochim Biophys Acta 1852: 1796-1804, 2015.

39. Strieter RM and Mehrad B: New mechanisms of pulmonary fibrosis. Chest 136: 1364-1370, 2009. 